\title{
Seismic Response Analysis on Continuous Beam One-way Slope Bridge with High and Low Pier in Mountainous Regions
}

\author{
Zheng Guodong ${ }^{1, a,}$ and Geng Bo ${ }^{2, b}$
}

\author{
${ }^{1}$ School of Civil Engineering and Architecture, Linyi University, Linyi, Shandong, PRC; ${ }^{2} \mathrm{China}$ \\ Merchants Chongqing Communications Research \& Design Institute Co., Ltd., Chongqing, PRC \\ azhengguodong@lyu.edu.cn, b18325499526@163.com
}

\begin{abstract}
Keywords: High and low pier, Continuous Beam, One-way Slope Bridge, Seismic Response Abstract. The internal forces at the end of pier, anti-push stiffness at the pier top, and seismic forces distribution law of one-way slope bridge with high and low pier, continuous beam and ordinary laminated rubber or lead-rubber bearing in mountains were analyzed by inputting EL-centro earthquake wave into 21 kinds of working conditions which were built on 3 kinds of boundary conditions and 7 kinds of piers with different height by adopting finite element analysis method. The results show that under the axial + vertical seismic action and transverse + vertical seismic action, the high pier with larger and smaller stiffness will respectively withstand major seismic loads, and with the increase of pier height, the seismic force gap between low and high piers is also increasingly larger; the earthquake forces of the pier bottoms along both directions can be reduced if the LRB is adopted, but the seismic isolation effect will gradually decrease until loses when the pier height raises to a certain value; the shock absorption effect is not obvious for the high pier with less stiffness of LRB and is obvious for the low pier with larger stiffness.
\end{abstract}

\section{Introduction}

With the implementation of the western development strategy of China, more and more bridges across the valley and mountain will be constructed. The difference between the regular bridge and the beam bridge with high and low piers in mountainous area can be distinguished by the difference of pier height from the macroscopic point of view. But in terms of the dynamic response characteristics and seismic design method under earthquake action [1], there is a big difference between them. Due to the complexity of the seismic response of the high and low piers bridge in the mountain area, it is often difficult to predict the response in the actual earthquake situation relying only on the current standard design.

At present, there are some achievements in the study of high piers [2-5]. However, there is no systematic research and analysis on the seismic response characteristics and seismic isolation of high and low piers. In the mountainous area, the unidirectional slope girder bridge, which is crossing the valley, deep ditch and hills, is serious uneven in mass and rigidity due to the height difference of adjacent piers. The seismic response of the bridge under the earthquake is very complicated and the seismic force distribution is not obvious. So it is very urgent to study the seismic response characteristics and seismic isolation. In this paper, the seismic response of unidirectional slope bridge with high and low piers under different bridge supports is studied, and some characteristics of seismic isolation design are obtained, which can provide reference for the design of similar type bridge. 


\section{Condition placement and earthquake input}

Now a $4 \times 40+4 \times 40$ first simply supported then continuously supported T-beam bridge (shown in Fig 1) is assumed. There are 4 holes and 3 expansion joints. The prestressed concrete T-beam with a beam height of $2.4 \mathrm{~m}$, a rib thickness of $0.2 \mathrm{~m}$ and a horseshoe width of $0.5 \mathrm{~m}$ is adopted in superstructure. The side beam width is $2 \mathrm{~m}$, the medium beam width is $1.8 \mathrm{~m}$ and the wet seam width is $0.65 \mathrm{~m}$. The full width of bridge structure is $12 \mathrm{~m}$. The rectangular pier (with a rectangular base) and pile foundation are used. The cap size is $7.5 \mathrm{~m} \times 7.5 \mathrm{~m}$ with a thickness of $3 \mathrm{~m}$. The 80-type and 160-type expansion joints are used at abutment and piers. Hollow pier is used in calculation. The transverse and along the bridge size is $2.5 \mathrm{~m}$ and $5.0 \mathrm{~m}$ with equal section.

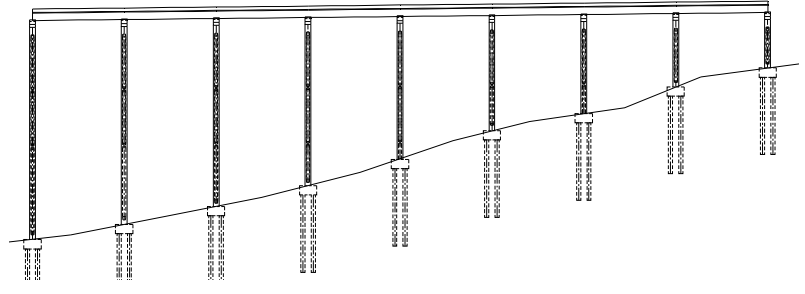

Fig1. Unidirectional slope Bridge

According to the type of bearing, three kinds of boundaries are analyzed in this paper. In the boundary 1 of the ordinary plate rubber bearing, the shear rigidity is set at the longitudinal bridge direction and the transverse bridge is fixed; in the boundary 2 of the ordinary plate rubber bearing. The middle pier is fixed and the else piers are set the shear stiffness in longitudinal direction, and all piers are fixed in transverse bridge direction.

In the boundary 3 of the lead-isolated rubber bearing, shear rigidities are both set along longitudinal and cross bridge direction. There are 9 conditions ( $i-j, i=1,2,3 ; j=1,2,3)$, where $i$ is the boundary condition number and $\mathrm{j}$ is the pier high number, as shown in Table 1.

Table1 Pier height layout at each condition

\begin{tabular}{ccccccccc}
\hline Serial number & $h_{1}(\mathrm{~m})$ & $h_{2}(\mathrm{~m})$ & $h_{3}(\mathrm{~m})$ & $h_{4}(\mathrm{~m})$ & $h_{5}(\mathrm{~m})$ & $h_{6}(\mathrm{~m})$ & $h_{7}(\mathrm{~m})$ & Adjacent height difference \\
1 & 15 & 20 & 25 & 30 & 35 & 40 & 45 & 5 \\
2 & 20 & 30 & 40 & 50 & 60 & 70 & 80 & 10 \\
3 & 25 & 40 & 55 & 70 & 85 & 100 & 115 & 15 \\
\hline
\end{tabular}

In this calculation, in three kinds of borders, two kinds of bearings are used to simulate them. The plate rubber bearing GYZF450 $\times 101$ type and GYZ650 $\times 130$ type are adopted. The horizontal stiffness and vertical stiffness of the plate rubber bearing can be calculated as $3493 \mathrm{kN} / \mathrm{m}$ (middle pier) and 2240kN / m (side) by [6]. Y4Q670 type and Y4Q470 type lead rubber bearing are used. By calculating the lead rubber bearing horizontal elastic stiffness and yield stiffness were $10800 \mathrm{kN} / \mathrm{m}, 162 \mathrm{kN}$ (middle pier) and $8100 \mathrm{kN} / \mathrm{m}, 81 \mathrm{kN}$ (side pier). In the time-history analysis in this paper, EL-centro wave is used, and the model has been motivated continuously. Seismic wave input is used in the following two ways: (1)transverse +0.65 vertical direction; (2)in longitudinal +0.65 vertical direction.

\section{Comparison and Analysis of Pier Bottom Internal Force}

Under the three boundary conditions, the seismic waves are input respectively in longitudinal direction + vertical direction and transverse + vertical direction. Through the calculation of the finite element program midas civil, the internal force values of the seismic response on the pier bottom section are obtained under each working condition. The bottom internal forces (shear and bending moments) under the same pier height are compared under different conditions, and the conclusions are as follows(shown in Fig 2 and Fig 3): 
(1)Under the $\mathrm{x}+\mathrm{z}$ earthquake and the boundary condition 2, the shear force of the bottom of the second fixed pier with the height of $20 \mathrm{~m}$ is larger than those at the other boundary conditions about 3 times. The pier bottom shear forces of the 6 \# fixed pier (with a height of $40 \mathrm{~m}$ ) and other piers are close. They are about $1 / 3$ of the shear force of the $2 \#$ pier, and the remaining trends are the same with the case 1 . Under the boundary condition 3, the bottom shear force of each pier is reduced to a lesser extent. When the seismic wave is put along the bridge, the $2 \#$ pier of each span bears most of the moment of the earthquake under boundary conditions 1,2. But with the increase in the height of the pier, the bottom bending moment reduces. Under the boundary condition 3, the bottom moment is reduced to a lesser extent.

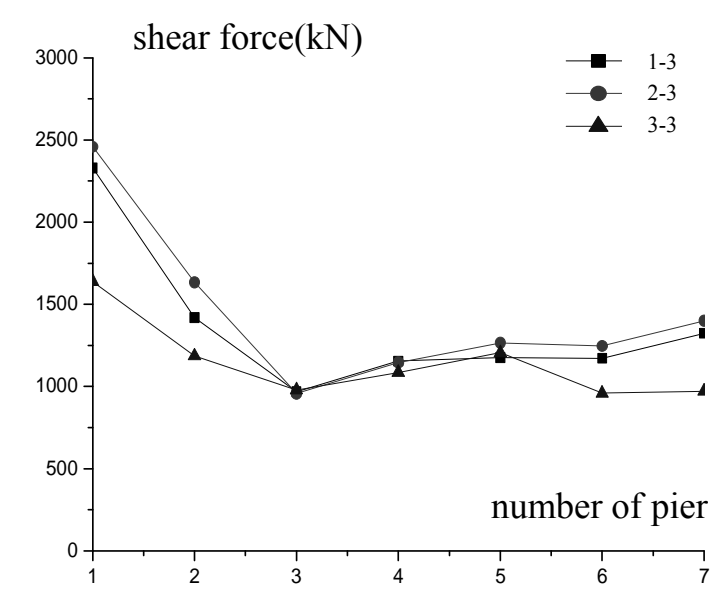

(a) $\mathrm{x}+\mathrm{z}$

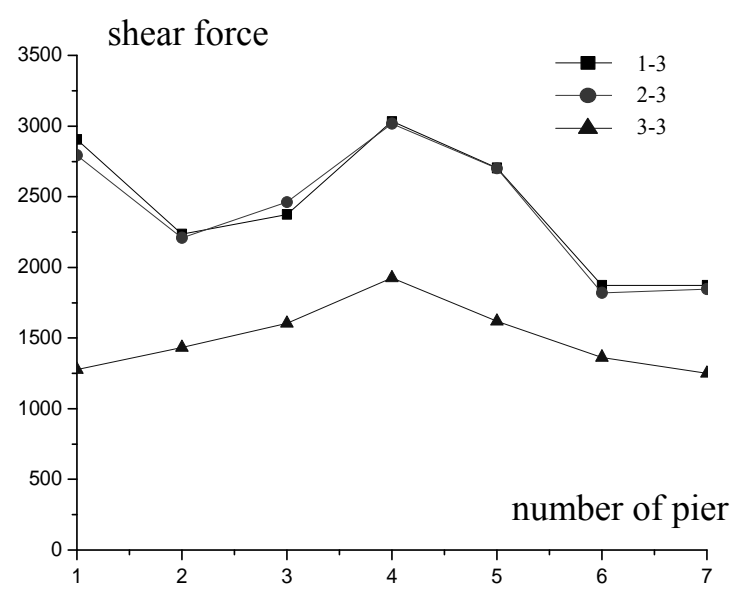

(b) $y+z$

Fig2. 1-3、2-3、3-3 shear contrast under earthquake working conditions

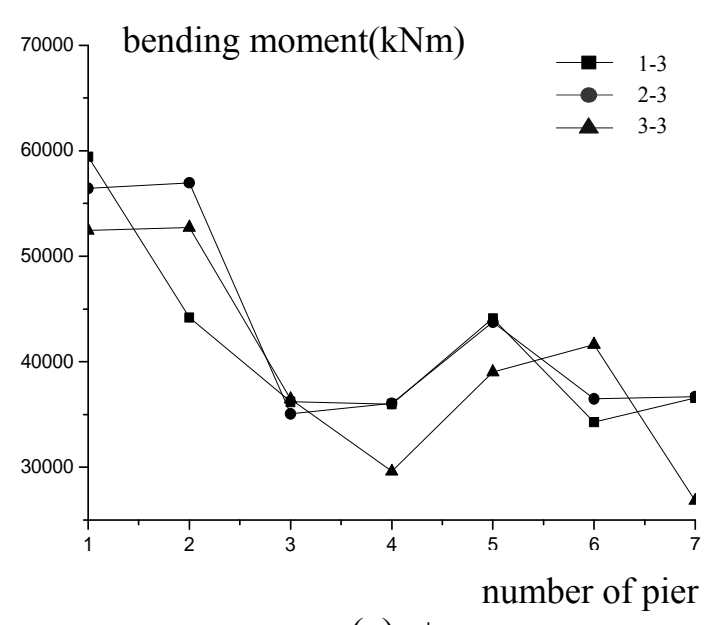

(a) $x+z$

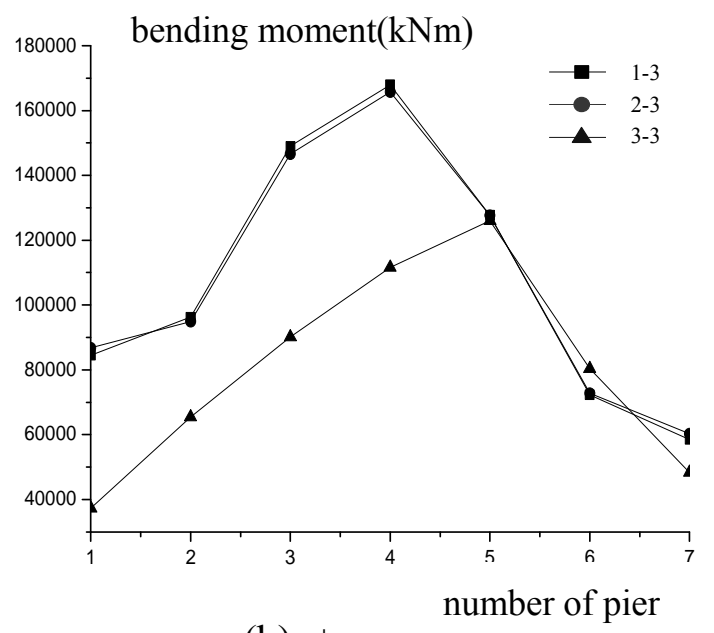

(b) $y+z$

Fig3. 1-3、2-3、3-3 moment contrast under earthquake working conditions

(2) Under the action of $y+z$ earthquake a nd boundary conditions 1,2 , the $\mathrm{W}$-shaped shear distribution tendency is shown in each working condition. That is, the shear force of the pier bottom of 1, 4 and 7 pier is large, and the rest is little. Under the boundary condition 3, each shear force of the pier bottom is obviously reduced, and the shock absorption effect is remarkable. Under boundary conditions 1 and 2 and the same conditions, bending moments of the piers are small at both ends and large in the middle. Overall, the pier moments are also gradually increased as the pier height increases, but when the height increases to a certain height, the bending moment reduces. Under the boundary condition 3, with the increase of the pier height, the shock absorption effect is obvious for the dwarf pier and gradually reduced with the pier height increased. 


\section{Calculation of anti-pushing rigidity of pier top}

The anti-pushing rigidity of pier top is the force required to produce the horizontal unit displacement of the pier at the top of the pier. In the mountains there are a large number of one-way slope bridge, bridges across valley and mountain and others. These bridges have a common characteristic, that is, adjacent bridge piers have a large height difference, so that the stiffness of the piers and the pier vibration cycles also have a large difference. The forces of beam bridges with high and low piers are not so even, regular and have similar dynamic characteristics as the beam bridge with the same pier height.

The bearings and piers can be seen as two different springs with different elastic coefficients. The connection between them can be regarded as the series of springs. It can be seen from the elastic mechanics that the elasticity $\mathrm{k}$ after their series is:

$$
k=\frac{k_{1} \times k_{2}}{k_{1}+k_{2}}
$$

Table2 anti-pushing rigidity ratio of pier top under boundary 1

\begin{tabular}{|c|c|c|c|c|c|c|c|c|}
\hline \multirow{3}{*}{$\begin{array}{c}\text { Working } \\
\text { condition } \\
1-1\end{array}$} & Height of pier(m) & 15 & 20 & 25 & 30 & 35 & 40 & 45 \\
\hline & $\begin{array}{l}\text { anti-pushing rigidity in longitudinal } \\
\text { combination }(\mathrm{kN} / \mathrm{m})\end{array}$ & 0.17 & 0.22 & 0.18 & 0.17 & 0.11 & 0.09 & 0.06 \\
\hline & $\begin{array}{l}\text { anti-pushing rigidity in transverse } \\
\text { combination }(\mathrm{kN} / \mathrm{m})\end{array}$ & 0.12 & 0.18 & 0.17 & 0.19 & 0.14 & 0.12 & 0.08 \\
\hline \multirow{3}{*}{$\begin{array}{c}\text { Working } \\
\text { condition } \\
1-2\end{array}$} & Height of pier(m) & 20 & 30 & 40 & 50 & 60 & 70 & 80 \\
\hline & $\begin{array}{l}\text { anti-pushing rigidity in longitudinal } \\
\text { combination }(\mathrm{kN} / \mathrm{m})\end{array}$ & 0.29 & 0.28 & 0.17 & 0.11 & 0.07 & 0.04 & 0.03 \\
\hline & $\begin{array}{l}\text { anti-pushing rigidity in transverse } \\
\text { combination }(\mathrm{kN} / \mathrm{m})\end{array}$ & 0.19 & 0.25 & 0.19 & 0.16 & 0.10 & 0.07 & 0.05 \\
\hline \multirow{3}{*}{$\begin{array}{c}\text { Working } \\
\text { condition } \\
1-3\end{array}$} & Height of pier(m) & 25 & 40 & 55 & 70 & 85 & 100 & 115 \\
\hline & $\begin{array}{l}\text { anti-pushing rigidity in longitudinal } \\
\text { combination }(\mathrm{kN} / \mathrm{m})\end{array}$ & 0.42 & 0.28 & 0.14 & 0.07 & 0.04 & 0.03 & 0.02 \\
\hline & $\begin{array}{l}\text { anti-pushing rigidity in transverse } \\
\text { combination }(\mathrm{kN} / \mathrm{m})\end{array}$ & 0.28 & 0.29 & 0.18 & 0.11 & 0.07 & 0.04 & 0.03 \\
\hline
\end{tabular}

Where $k$ is the anti-pushing rigidity on the pier top; $k_{1}$ is the anti-pushing rigidity of the pier body, $k_{1}=3 E I / l^{3} ; \mathrm{E}$ is the elastic modulus of the pier; $\mathrm{I}$ is the inertia moment of cross section of the pier; 1 is the pier height; $G$ is the shear modulus of rubber bearing; $A$ is the rubber bearing area $\left(\mathrm{m}^{2}\right) ; t$ is the total thickness of rubber layer of plate rubber bearing $(\mathrm{m}) ; m$ is the rows number of pier bearing; $n$ is the number of bearings in a single row, and the elasticity of the bearing is $k_{2}=m n A G / t$.

From the formula (1), the anti-pushing rigidities of pier top of continuous rigid frame bridge under various boundary conditions is calculated. In order to make the analysis more clear and intuitive, the anti-pushing rigidities of pier top under the same condition are normalized treated (that is, each pier is regarded as to be paralleled with the main beam and the ground, so the total stiffness of the bridge is equal to the sum of the stiffness of the piers. The ratio of the stiffness of each pier to the total stiffness respectively is obtained), and the ratio of the anti-pushing rigidities of pier top is obtained. In working condition 2, the bearing of middle pier top in each league will be assumed to be fixed along and across the bridge, and the rest of the bearing layout is the same with the working 
condition 1 . For the fixed pier, the pier is rigidly connected through the fixed bearing with the upper structure. The rigidity of fixed bearing can be regarded as infinite, that is $\mathrm{k} 2$ tends to infinity. We can get $\mathrm{k}=\mathrm{k} 1$ with (1), that is, the anti-pushing rigidities of fixed pier and pier top are equal. The anti-pushing rigidities of pier top under working condition 3 can be obtained similarly. Table 1 lists the rigidity ratios under working condition 1.

\section{Conclusions}

(1) Under the action of longitudinal direction + vertical earthquake, the lower pier with large rigidity is subjected to the main seismic load. On the whole, with the increase of the pier height, the difference of the seismic force between the low pier and the high pier is larger and larger. Under the action of transverse bridge + vertical earthquake, the high pier with smaller rigidity will bear the main earthquake load, and with the increase of the pier height, the gap between the low and high pier is bigger and bigger.

(2) Under the action of longitudinal direction +vertical earthquake, the seismic force of the pier bottom can be reduced by the use of the lead-bearing rubber isolation bearing. As the pier height increases, the isolation effect will be gradually increased. But when the pier height increased to a certain height, the isolation effect of the lead rubber isolation bearing will be gradually reduced until the loss of isolation effect, and the end of the seismic force will be greater than the pier without it. Under the action of transverse bridge + vertical earthquake, the situation is the similar.

(3) The shock absorber effect of the high pier of the lead bearing rubber bearing with small rigidity is not obvious, but is obvious for the low pier with large rigidity. So the lead rubber bearing can only be set in the low pier, side pier and abutment, which can make the layout of the isolation measures more economical and reasonable.

\section{References}

[1] Chen Jintao. "Study on seismic Behavior of Prestressed Concrete Continuous Rigid Frame Bridge with High-Pier and Large-Span”. Chang'an University, 2011

[2] Li Zheng, Li Zhongxian. "Seismic damage analysis of RC high bridge piers using a modified elastoplastic damage model”. China Civil Engineering Journal. 2011.44(7):71-76

[3] SUN Zhuo, LI Jianzhong, YAN Guiping, FAN Lichu. "Experimental Study on Seismic Performance of Reinforced Concrete One-Column Bridge Piers". Journal of Tongji University(Natural Science), 2006.34(2):160-164

[4] WANG Bo, ZHANG HaiLong, XU Feng. "Parametric Study of Seismic Time-history Response of High-rise Thin-wall Pier and Long Span Rigid Frame Bridges". Central South Highway Engineering, 2007.34(4):28-36

[5] CHEN Yang-yang, CUI Jie, LIU Bo, ZHOU Fu-lin. "A Theoretical Study on the Horizontal Dominant Vibration Mode of a Girder Bridge with Tall Piers". Journal of Vibration and Shock, 2008.27(7):63-68

[6] Ministry of Transport of the PRC. "Series of Elastomeric Pad bearings for Highway Bridges (JT/T663-2006)". (China Communications Press, Beijing 2006) 